\title{
Making the Right to Health a Reality for Brazil's Indigenous Peoples: Innovation, Decentralization and Equity
}

\section{Vera Coelho PhD and Alex Shankland DPhil}

\begin{abstract}
This article provides an overview of governance arrangements and changes in the Brazilian public health system since 1988, when the "Citizen's Constitution" declared health to be a universal right. Since then, population coverage has grown substantially and health indicators have improved. Despite these achievements, inequities in access remain an important barrier to universal coverage, in particular for marginalized groups such as indigenous peoples. This article discusses the innovation cycle that produced the gains and recent efforts to guarantee more equitable access to health services for the indigenous population in a continent-sized country historically plagued by great inequalities.
\end{abstract}

KEYWORDS Health care systems, indigenous health services, access to health care, health policy, healthcare disparities, inequalities, indigenous population, Brazil

\section{HEALTH INEQUITIES AND THE BUILDING OF THE UNIFIED HEALTH SYSTEM}

Brazil's public health system was created in the 1930s and grew significantly between 1964 and 1986 during the military regime. However, in the 1980s the system became the focus of important criticisms, particularly that it did not provide universal coverage; too many resources were allocated to highly complex procedures instead of primary care; and richer regions had more resources, facilities, and services. In sum, richer citizens living in better-off regions had much better access to the public health system.[1,2]

In 1988, with the return to democracy, a new constitution, known as the "Citizen's Constitution," declared health a universal right of citizenship and replaced the old public health system with the Unified Health System (SUS, its Portuguese acronym).[3] The creation of the SUS reflected the aspirations of a national and international movement for 'health for all' and for a system that integrated local, state and national levels, as well as preventive with curative medicine.

Yet the SUS initially lacked at least two of the institutional mechanisms needed to turn these aspirations into reality: a) a model of medical care that integrated primary, secondary and tertiary care; and b) a legal and administrative framework defining the financial and service responsibilities of federal, state, and municipal governments. These were developed mainly in the 1990s, through:

- A local innovation process-prompted by crises in the earlier highly centralized and hospital-centered public health systemthat allowed for creation of decentralized programs by civil society and municipal or state authorities, which would thus be tested before becoming national in scope: examples include programs in primary care and HIVIAIDS prevention,

- Establishment of a clear division of labor among the National Ministry of Health (MS, the Portuguese acronym), states and municipalities, including signed agreements defining responsi- bilities and transparent financing rules for national policy implementation. In this arrangement, the MS provides nearly $55 \%$ of total funding and sets policy but does not directly deliver services; the remaining $45 \%$ of funding is covered by states and municipalities, which are required to allocate at least $12 \%$ and $15 \%$, respectively, of their revenue to health services.[4]

- Establishment of a National Health Council and subnational health councils - the latter now in all 26 states and in nearly all 5561 municipalities_as a result of mobilization by Brazil's health reform movement through health policy conferences, which advocated for effective institutionalization of citizen participation and oversight. Civil society represents $50 \%$ of participants in the councils at every government level; service providers, 25\%; and public officials, $25 \%$. They address core issues of priority setting and accountability and can challenge health system managers or policies, rather than merely participating in implementation. Fora for bringing municipal, state, and federal authorities together to discuss policies and budget allocations have also been created. These play a decisive role in regularly engaging civil society and health authorities and in facilitating flow of information across municipal, state, and federal levels.[5,6]

- Transfer of basic health services management to the local level: the proportion of municipalities responsible for expanded primary care program coverage increased from $23.4 \%$ in the mid-1990s to $88.7 \%$ in 2010.[7] Increased use of public-private partnerships and outsourcing have also facilitated implementation of these programs.

The cycle described above-from local innovation, to federal programs and scaling up, and back down to local implementation-helped ensure dissemination of innovative experiences through the health system and clarify jurisdictional responsibilities. The MS establishes national guidelines for health care at all three levels of complexity (basic, intermediate and high) and provides financial support to states and municipalities. States coordinate services provided within their territory, linking basic, intermediate, and highly complex services. Municipalities are responsible for provision of basic care and referral of patients to more complex services. This approach has helped address interregional inequalities, promoting coordination among levels of government and responsiveness to regional needs.[8]

Early receptivity to innovation and clear division of labor among spheres of government contributed decisively to ensuring implementation of successful large-scale changes that strengthened primary care and reduced regional inequalities in access. These achievements can be seen in Figures 1 and 2 .

Figure 1 shows growth in population coverage by the Family Health Program (FHP) primary care initiative and related health gains. In 1998, 3 million users were registered with FHP, rising 
Figure 1: Population covered by Family Health Program in Brazil, 1998-2010

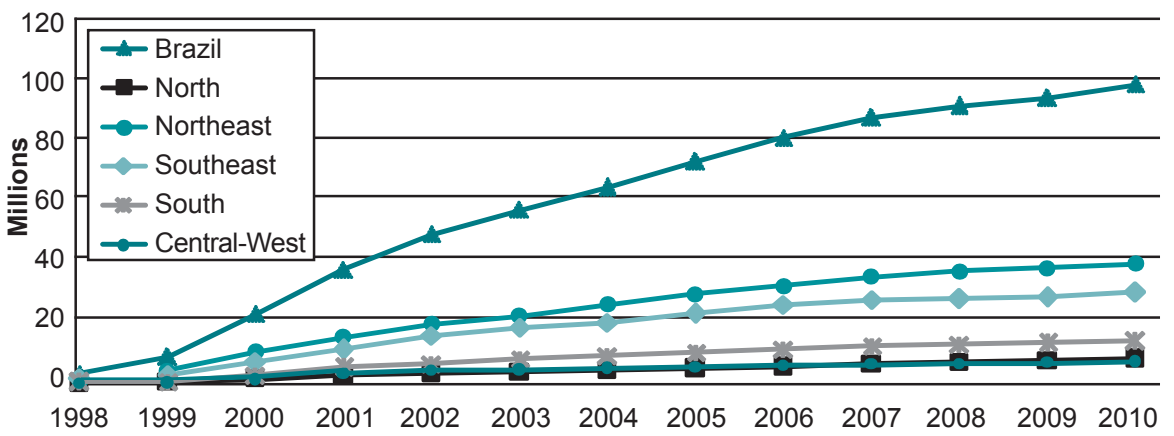

Source: Brazilian Ministry of Health Basic Care Information

Figure 2: Infant mortality in Brazil, 2001-2009

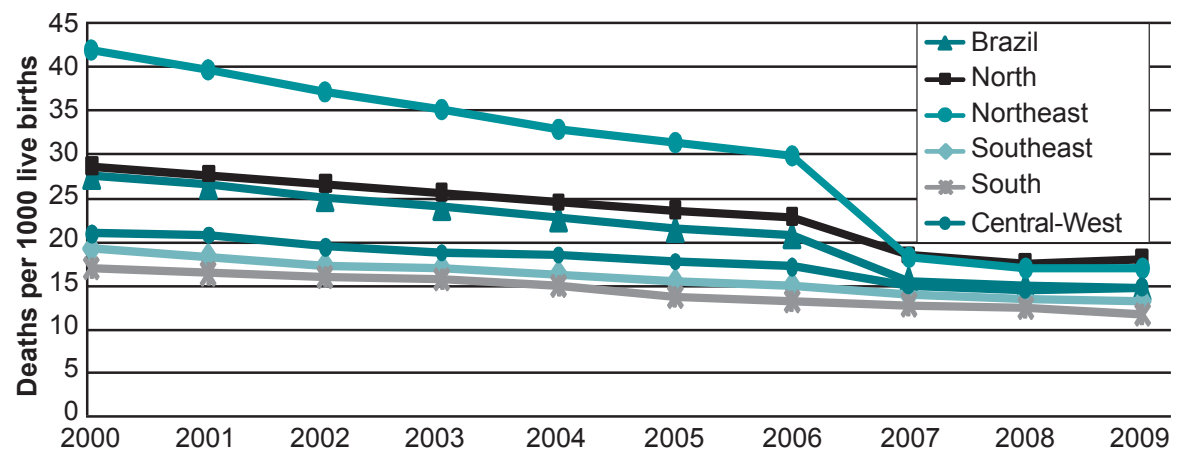

Source: Brazilian Ministry of Health Basic Care Information

Figure 3: Brazil's Special Indigenous Health Districts, 2010

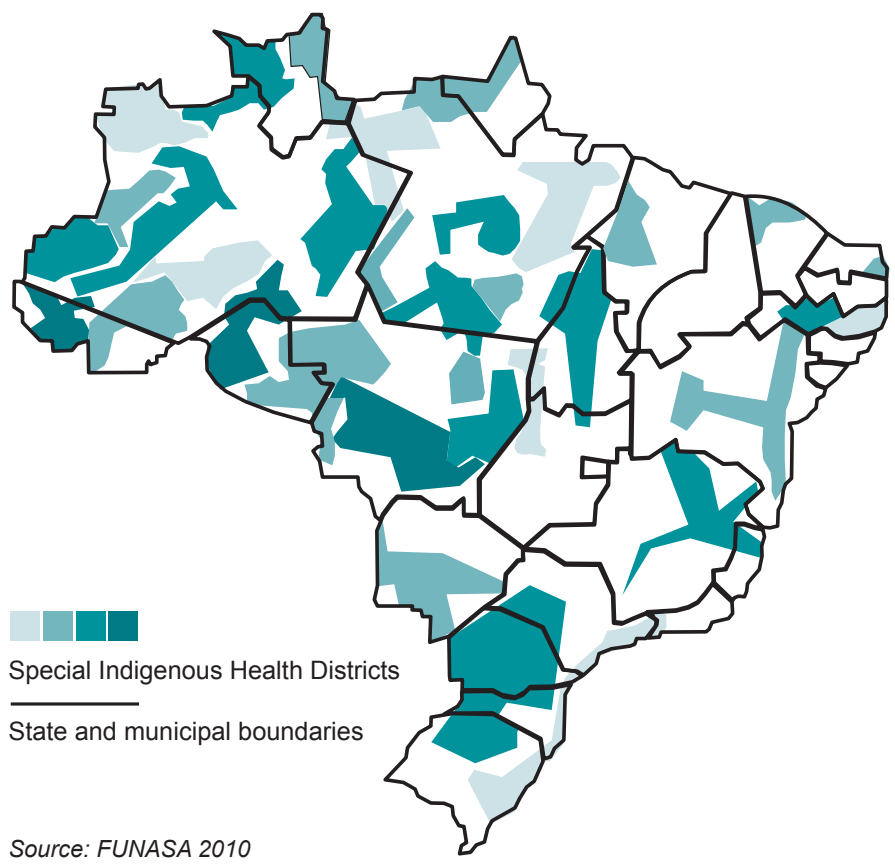

to 100 million in 2010, from a population of 190.7 million. This achievement certainly contributed to the impressive decline in Brazil's infant mortality from 2000 to 2009 shown in Figure 2, especially notable in the Northeast, traditionally the region with the highest rates, with a corresponding reduction of health inequalities between richer and poorer regions.[9]
Parallel to these achievements, more detailed data have been produced and publicized, making clearer the magnitude of inequalities between health conditions in the general population and those of specific ethnic groups, in particular Afro-descendent and indigenous people. For example, in 2000, mortality among indigenous infants was more than triple that of the population as a whole, as was tuberculosis incidence. $[10,11]$ A discussion of the quality of health statistics for indigenous peoples in Brazil is beyond the scope of this paper; see Menegolla.[12]

Despite growing debate during the 1990s about how to address these inequalities, there were difficulties in moving toward solutions.[13] For health authorities and the health reform movement, there was the dilemma of how to address specific ethnic groups' problems without jeopardizing the system's principle of providing the same care to all and not targeting one population group over another for specific services or special attention. In fact, there was much resistance within some sectors of the MS to differentiating services on the basis of cultural or ethnic identities, an idea that was perceived as fragmenting the system. Mobilization by black and indigenous people since the late 1980s and their active pursuit of demands for more targeted policies through the SUS's citizen participation mechanisms have been decisive in winning the creation of a number of federal and state programs focused on their specific needs.[14]

One of these programs was launched in the early 1990s with the Yanomami people of the Northern Amazon, who were facing extremely high mortality from malaria and other infectious diseases.[15] Mobilization by indigenous leaders and their health reform allies was consolidated through regional events promoted by the HIV prevention section of the MS to train these leaders in taking responsibility for implementing health programs at local level. These leaders also participated in local, state, regional, and national indigenous health conferences, calling for extension of the Yanomami-managed district model across Brazil.[16]

\section{THE INDIGENOUS HEALTH SUBSYSTEM}

In 1999, the MS received legislative approval to implement an Indigenous Health Subsystem comprising 34 Special Indigenous Health Districts. As seen in Figure 3, these districts were designed to reflect the fact that territories populated by indigenous peoples cross municipal and sometimes even state boundaries.[16]

Beginning in 2000, management of the Subsystem was decentralized to the Special Indigenous Health District level under overall responsibility of the National Health Foundation (FUNASA, its Portuguese acronym), an executive agency of the MS. Districts were responsible for organizing basic services in indigenous areas and for referring patients to more complex services. A mix of mainly NGO providers managed by FUNASA 
was responsible for delivering free primary care, while health authorities remained in charge of organizing patient referral to SUS-affiliated hospitals and clinics.[16]

In a number of cases, decentralization led to more in-depth work with local communities to build understanding about needs and cultural specificities and how to tailor services to them. This approach also revealed the potential complexities of health representations and why it is hard for standardized across-the-board prevention and care programs to be successful in such different sociocultural settings.

One example was development of STI/AIDS control programs with the Wajãpi people of the Northern Amazonian state of Amapá. The Wajãpi people were generally quite resistant to FUNASA's initial attempt to introduce condoms. The reasons were identified in Rosalen's anthropological study, which described the Wajãpi belief in a vital principle that provides life to the body and finds support for its circulation in bodily fluids, including sperm; in the Wajãpi's socio-cosmological belief system, keeping sperm in a container such as a condom will weaken a man's body by holding back his vital principle.[17] A team of specialists that had been working among the Wajãpi for years organized a number of awarenessraising activities that made progress possible. Through a sensitive approach to native cultural beliefs and practices, they were able to understand and overcome the contradictions between the Wajãpi's representations and practices and those of Western biomedicine. $[18,19]$

In the decade following creation of the Subsystem, annual investment in indigenous health grew five-fold, providing key resources. In fact, annual spending on indigenous health reached US $\$ 450$ per person, five times the annual per capita expenditure by the SUS on primary care for the population as a whole.[20]

As a result of a more sensitive and flexible approach, backed by increased spending, the Subsystem achieved a sharp initial decline in infant mortality and tuberculosis incidence among indigenous populations.[10,12] However, from 2004 on, management problems and growing accusations of corruption against NGOs led to a breakdown of trust among FUNASA, NGOs and indigenous leaders. These factors, coupled with great practical difficulties in harmonizing the work of the Special Indigenous Health Districts with that of the municipalities, triggered recentralization by FUNASA, including a return to a less flexible standardized "one size fits all" approach, with slower gains in health indicators despite continued steep spending increases.[12] This, in turn, triggered further protests by indigenous groups, which continued until late 2010 , when the government finally removed responsibility from FUNASA and created a new Special Secretariat for Indigenous Health, located in the MS and tasked with ensuring service quality while promoting greater management autonomy at the district level.[21]

\section{TAKING STOCK: LESSONS LEARNED}

Mobilization by indigenous movement organizations and their allies has succeeded in securing recognition of indigenous demands for targeted service provision. Indigenous representatives and allied NGOs and specialists argued for the need to focus not on simple inclusion but rather on transformation of the health care system to accommodate the principle of interculturality, that is, working in different sociocultural settings in mutual respect. The subsystem brought a new layer to the public health system, the
Indigenous Health Districts, which opened new possibilities for better targeting and addressing indigenous peoples' needs, but also posed new coordination and distributive challenges.

Overall spending on indigenous health rose significantly in the decade following the creation of the Indigenous Health Subsystem, far outstripping provisions made for other poor Brazilians living in rural areas. This has contributed to overall improvements in indigenous health indicators, although the stalling of innovation in recent years has reduced the impact of increased spending, and indigenous Brazilians continue to have by far the worst health status of any population group-as shown, for example, by the rates of infant mortality and of deaths caused by infectious and parasitic diseases that until recently were twice the Brazilian average.[12]

The problems faced by the Indigenous Health Subsystem relate both to its institutional fragilities and to resistance by some sectors of the MS to internalizing nonstandard approaches and transforming the practices of the SUS, the latter noted for its defense of achieving universal coverage through rollout of standardized programs. From our perspective, a careful analysis of the Indigenous Health Subsystem experience may not only help restart the cycle of innovation within the Subsystem, but also help the wider SUS respond to demands for quality and equity, important to other sectors of Brazil's poor.

In sum, indigenous and pro-indigenous organizations are challenging the way health programs are defined. They argue that while coverage has expanded, there has been little recent progress in changing the content of newly-available services to reflect indigenous practices and values. The MS in turn emphasizes the necessity of ensuring continuity and universality, avoiding fragmentation of service provision among local, specific, and short-term interventions. Government representatives have also criticized a perceived lack of accountability and financial transparency on the part of NGOs and other not-for-profit service providers.

These different perspectives highlight the complexities of organizing a system responsive to both the cultural specificities of the indigenous communities and the SUS's universal character as defined by access of all people to the same services.

\section{CREATING AN EVIDENCE BASE TO MOVE AHEAD}

To reinvigorate the cycle of innovation needed to guarantee quality and equity, we need to make use of what we have already learned from the SUS and the Indigenous Health Subsystem implementation processes.

This understanding guided the approach taken by the Brazilian Center for Analysis and Planning, a Brazilian social policy think tank; the Institute of Development Studies at University of Sussex in the UK; and the Brazil Health Unlimited Association, an NGO specializing in indigenous health policy and service delivery, when the consortium formed by the three organizations was commissioned by the MS to lead a consultancy process aimed at designing appropriate models for the Indigenous Health Subsystem.

This methodology included regional workshops with several hundred participants-mainly indigenous people, public health man- 
agers, local politicians and service providers-and was framed as a learning process rather than a prescription for practice, seeking to stimulate horizontal exchange for sharing reflection and spreading innovation.[12]

The creation of the new Special Secretariat for Indigenous Health may present an opportunity to test the consultancy's recommendations, which highlighted three key issues:

First, to promote autonomy and responsiveness to local needs, it is important to define more precisely the roles of the different authorities over administrative and clinical issues. It will also be crucial to identify in each of the different institutions a clear lead person with a defined responsibility for delivering on agreed targets.

Second, once these roles and leaders are more clearly identified, it will become easier to promote coordination through development of instruments (contracting and other negotiation processes) to facilitate effective partnerships among the federal government, states, municipalities, NGOs, district teams, and indigenous communities. The federal government will need to invest in strengthening local partners' capacity through appropriate training and technical support. Similarly, health authorities at all levels will need to ensure that incentives (financial, career structure, access to training, status) encourage actions consistent with achievement of the Subsystem's goals (effectively delivering culturally appropriate basic services and guaranteeing equitable access to more complex services).
Third, to promote accountability and innovation, it is also important to improve mechanisms of social oversight and service user engagement. Existing oversight mechanisms are very bureaucratic and limit options for indigenous users to have input into district priorities and provide feedback on health services performance, including cultural appropriateness. In contrast to municipalities, indigenous health district managers (who are appointed by central government and not locally-elected politicians) are not exposed to sanctions through the ballot box; this means that other mechanisms for promoting accountability and responsiveness need to be developed. From this perspective, public involvement may encourage innovation and learning from successful and unsuccessful initiatives.

These recommendations largely reflect the experience of the wider SUS, which has managed to maintain its innovation cycles by balancing decentralization and participation with strong central guidance and support for scaling up local innovations. In this case, the SUS's Indigenous Health Subsystem is working toward a more tailored or flexible approach that recognizes the importance of the differences and inequalities among population groups, and not just among localities. Acknowledging and tackling this challenge is, in our view, one of the most important tasks facing the Brazilian health system today. The way in which the SUS responds may generate valuable lessons for policy makers elsewhere in the world who are grappling with the challenge of achieving health equity in highly unequal multi-ethnic societies. -1 -

\section{REFERENCES}

1. Coelho V, Silva N. Has the distribution of public health services become more equitable? Reflecting on the case of São Paulo. In: Shantayanan S, Widlund I, editors. The Politics of Service Delivery in Democracies. Better Services for the Poor, 2007. EGDI. Ministry for Foreign Affairs. Stockholm: Ministry of Foreign Affairs (SE); 2007.

2. National Commission on Social Determinants of Health (BR) [Internet]. Rio de Janeiro: Technical Secretariat CNDSS; c2006 [cited 2011 Feb 1]. Available from: http://www.determinants.fiocruz. br/acoes.asp

3. [Constitution of the Federative Republic of Brazil, Art. 190-200.] 1988. Portuguese.

4. Uga MA, Piola SF, Porto SM, Magalhães SV. [Decentralization and resource allocation in the Brazilian Health System (SUS)]. Ciênc Saúde Coletiva. 2003;8(2):417-37. Portuguese.

5. Cornwall A, Shankland A. Engaging Citizens: Lessons from Building Brazil's $\mathrm{Na}$ tional Health System. Soc Sci Med. 2008 May;66(10):2173-84.

6. Coelho V. Brazilian Health Councils: including the excluded? In: Coelho V, Cornwall A, editors. Spaces for Change? The Politics of Participation in New Democratic Arenas. London: Zed Books; 2006.

7. Ministério da Saúde (BR). [Evolution of the population covered by Family Health teams] [Internet]. Brasilia: Departamento de Atenção Básica. Brasilia; 2010 [cited 2011 Feb 1]. Available from: http://189.28.128.99/dab/caa/. Portuguese.

8. PAHO. Brazil Health Systems and Services Profile. Brasilia: Pan American Health Organization; 2008.

9. Ministério da Saúde (BR). Health Data 2010 [Internet]. Departamento de Informática do SUS 2010 [cited 2011 Feb 1]. Available from: http:// tabnet.datasus.gov.br/tabnet/tabnet.htm. Portuguese.

10. Ministério da Saúde (BR). [Brazil 2006: An analysis of Health Inequalities]. Brasilia: Ministério da Saúde(BR); 2006. Portuguese.

11. UNICEF. The State of Brazil's Children 2006. Brasilia: UNICEF; 2005.

12. Menegolla I. [Epidemiological profile of indigenous populations in Brazil]. In: Consórcio IDS-SSL-Cebrap Diagnóstico Situacional da Saúde Indígena no Brasil. Consultancy report [Internet]. Brasilia: FUNASA; 2009 Apr [cited 2011 Feb 1]. 231 p. Available from: http:// www.funasa.gov.br/internet/arquivos/vigisus/ vigModSsi_DiagnosticoSSI.pdf. Portuguese.

13. Shankland A, Cornwall A. Realizing Health Rights in Brazil: The Micropolitics of Sustaining Health System Reform. In: Bebbington A, McCourt W, editors. Development Success: Statecraft in the South. Basingstoke (UK): Palgrave Macmillan; 2007.

14. Coelho V, Lavalle A, Spink P, Aquino M. Creating Systemic Change: Fighting Poverty through Accountable Policy Processes. Research Report. São Paulo: [publisher unknown]; 2010.

15. Menegolla IA, Lobo MSC, Pithan OA, Vargas I, Ramos AR. [Yanomami Health District -Activity Report and Health Situation Assessment]. Boa Vista: Ministério da Saúde (BR); 1992. Portuguese.

16. Garnelo L, Macedo G, Brandão LC. [Indigenous Peoples and the Building of Health Policies in Brazil]. Brasilia: Pan American Health Organization; 2003. Portuguese.

17. Rosalen J. [Approaching the HIVIAIDS thematic among the Wajãpi of Amapari] [dissertation]. [Sao Paulo (BR)]: University of Sao Paulo; 2005. Portuguese.

18. Apina. [STD/AIDS Prevention and Care for the Waiãpi indigenous people of the Municipality of
Pedra Branca do Amapari. Brasília: Apina Consultancy Report]; 2003. Portuguese.

19. Apina. [STD Prevention in the Wajãpi indigenous land. Brasília: Apina Consultancy Report]; 2005. Portuguese.

20. Portal da Transparência [Internet]. 2009 [reviewed 2010; cited 2011 Feb 1]. Available from: http://www.portaldatransparencia.gov.br/

21. [Constitution of the Federative Republic of Brazil, Decree No 7.336, Art. 5-6]. (Oct 19 $9^{\text {th }}, 2010$ ) Portuguese.

\section{THE AUTHORS}

Vera Schattan Coelho (Corresponding author: veraspc@uol.com.br), social scientist. Research Director, Brazilian Center for Analysis and Planning, São Paulo, Brazil.

Alex Shankland, social scientist. Research Fellow, Institute of Development Studies, University of Sussex, Sussex, UK.

\author{
Submitted: March 2, 2011 \\ Approved for publication: July 3, 2011 \\ Disclosures: None
}

